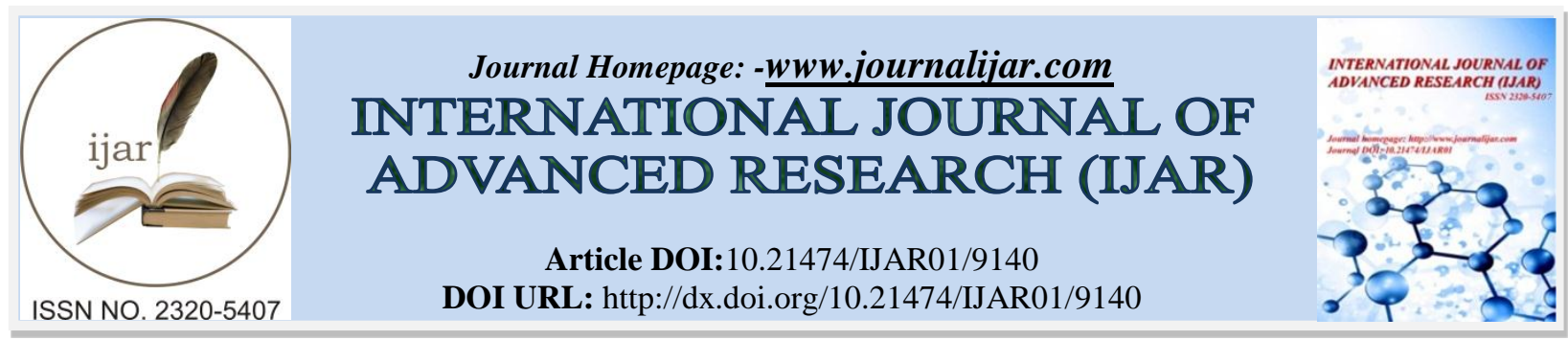

RESEARCH ARTICLE

\title{
A STUDY OF SOLAR POWERED WATER PUMPING SYSTEM USING PVSYST.
}

Richa Khera $^{1}$, Anita Khosla ${ }^{1}$ and Dheeraj Joshi ${ }^{2}$.

1. EEE Department, Manav Rachna International , Institute of Research \& Studies.

2. EEE Department, Delhi Technological University, Institute of Research \& Studies.

\section{Manuscript Info}

Manuscript History

Received: 24 March 2019

Final Accepted: 26 April 2019

Published: May 2019

\section{Key words:-}

Solar energy , Power Converter,

Maximum power point tracking

,Brushless DC Motor.

\begin{abstract}
Due to the depletion of fossil fuels renewable energy sources are gaining the utmost importance. As solar energy is available in abundance so it is one of the main source of energy .This spark is also due to reduction in the cost of the Photovoltaic cell (PV) which is the result of technological advancement in the field of power electronic. There are numerous application for the solar energy .One of the application is in the field of water pumping system which earlier incorporated diesel prime mover. But the advancement in technology resulted in the advancement in of solar based water pumping system. To improve the efficiency of the water pumping system and to estimate the cost and performance the pre-sizing of the system is done. In this paper software PV syst used for the pre-sizing of solar based water pumping is studied. The detailed simulation steps are used in this software tool are discussed in this paper. The paper deals with the process involved in presizing of solar based water pumping system using PV syst while considering Maximum power point tracking converter and brushless DC Motor.
\end{abstract}

Copy Right, IJAR, 2019,. All rights reserved.

\section{Introduction:-}

Due to increase in the population the water supply problem has been increasing in the developing countries .Also due to the depletion in the fossil fuels the renewable energy sources are gaining the utmost importance. Solar water pumping system is one of the main solution for the current scenario But the main hurdle is to size and optimize the pumping system Generally the manufactures use some or their own standard system configuration for analysis of the performance of the pump during the day

There is a tool PV syst that helps in the presizing of the system and also give the detailed report of the system performance and efficiency. This software package do the design analysis for the grid connected system, standalone system and Water pumping system. The aim of this paper analyze detailed water pumping system .

\section{PRE-Sizing Using PVsyst tool}

The water pumping system involves may variables and has different operating conditions during the day due to the orientation of the sun and in the whole year due to seasonal variations so sizing of the system becomes complex task.

Corresponding Author:-Richa Khera.

Address:-EEE Department, Manav Rachna International, Institute of Research \& Studies. 
The data such as volume of the water needed in the year, the level difference from which the water is pumped known as head are to be given by the user. The user also specifies the duration during which he can water needs are not met can be acceptable. So based on these data ,PV syst simulation package is able to estimate the size of the system. The software gives the quick yearly evaluation of type of solar array to be used ,pump size, tank volume that will be needed to fulfill the water needs. This also evaluates the performance which can be increased by using the appropriate technology .The cost analysis can also be done.

The simulation process runs over one year based on the day to day need. The software package uses in built meteo database or meteo files which can be loaded to determine the effect of the solar irradiance .

This imitation route is reworked with assortment of PV, pump size until coordinating the client's prerequisites is depicted in the result which are basically monthly yield ,missing water. This early simulation is followed by the detailed simulation using the real time data which contains many variables.

\section{The Simulation Procedure}

A pumping system generally shows the highly non linear behavior. The pump starting threshold value, mismatch in PV array-pump electrical characteristics, converter efficiency, characteristics of well, operating limits etc. are the variable which have to be observe. So the manufacturer data is incomplete for the accurate performance evaluation. This problem has been resolved to some extent by using simulation tool called PV syst.This provides the step by step evaluation over the realistic data. The software package provides the framework of such simulation over the hourly needs of the user and the data taken from the meteo files.It also do the detailed modeling of the components.

\section{Requirements of the pumping System}

The following features should be taken into the account while simulation :

1. Defining the water necessitates of the client and it is in terms of seasonal or monthly values[1]

2. if using storage reservoir, characteristics to be defined

3. Dynamic behavior which includes the extreme limits should be specified.

4. Photovoltaic vivacity yield (counting meteo information, plane introduction, "PV" cluster qualities, gloominess and so on) ought to be known.

5. the motor and pump to be used is determined[2]

6. Regulation and power converters strategy should be known,

\section{Steps for the Analysis}

Defining the orientation of the panel:

The data for the irradiance has been taken from the meteo file data base which is available in the software or can be import from the external sources in the system. The heart of the system is the designing part.. In this first the orient of the PV panels mounted is assigned. There are options in the field type like fixed tilt ,seasonal tilt, tracking tilt from which appropriate has been chosen. Azimuth angle is also selected.

\section{Setting the System configuration:}

First of all theamount of the water required has been entered by taking the water needs button page on the "Pumping Hydraulic Circuit". There are three options available for defining the pumping circuit from which one is chosen

1. Pumping by making "Deep well" constituting storage tank

2. Pumping water from a lake or river to the tank storage

3. For the distribution of the water pumping the water into the harried tank next in this is to define Hydraulic Circuit configuration

As the solar output is not always constant the storage tank is always required for the pumping system so as to store available water and distributing it to the users.

The user should define:

1. The volume o the storage tank.

2. The diameter of the tank

1. The storage tank volume

Hydraulic circuit configuration is shown in figure 1

$$
\mathrm{D}=\text { Sqrt (Length*Width*4/Pi) }
$$

Diam $=$ SQRT $($ Length $*$ Width $* 4 / \mathrm{Pi})$ 


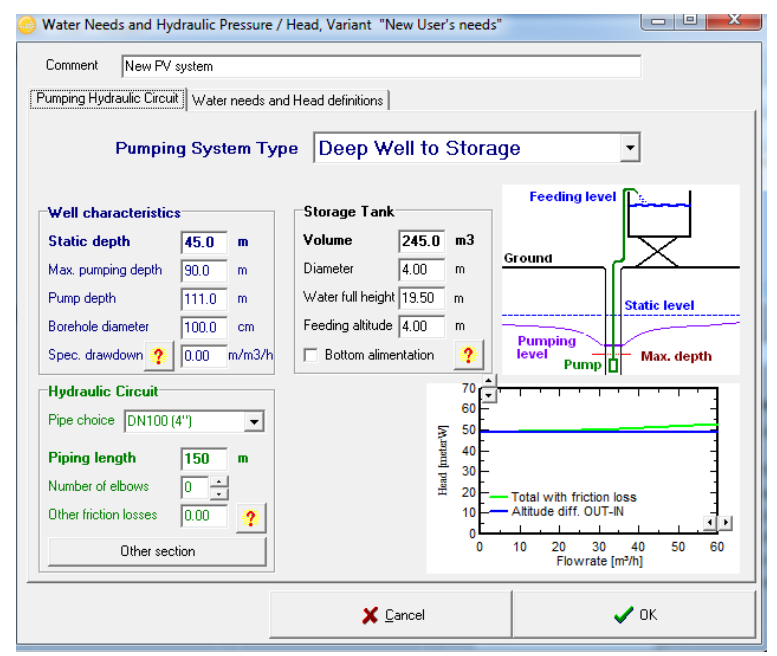

Figure 1:-Pumping hydraulic Circuit

Total head Calculation and modeling of well:

The summation of the resistance undergone by the pumped water is basically the total Dynamic head..TDH represents the Static head: It is the measure of the vertical distance that water will travel .It is the difference between the water source and water pump in case of submersible pumps but in case of surface mounted pump it is the difference between the height of the top of the water source and eater final destination.

\section{Dynamic Head:}

It is due the friction offered to water in pipes. This depends on the flow rate, diameter of pipe, length and material of the pipe.

In case if it is considered that pump is immersed in the well and reference is taken from the ground then the THD is shown in figure 2 .

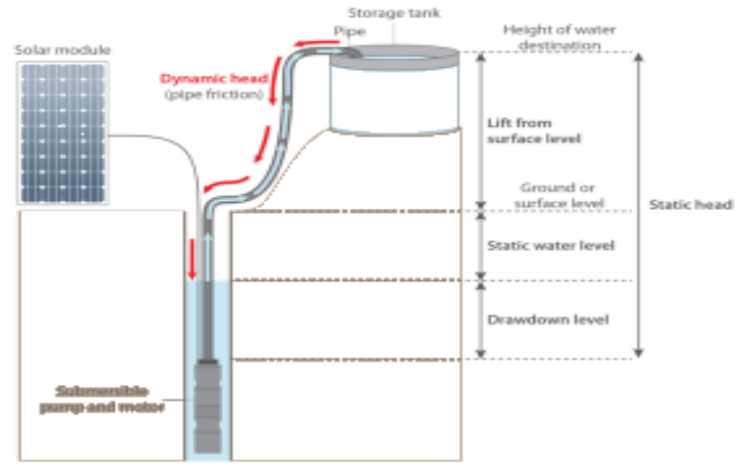

Figure 2:-Dynamic Head representation

Total Dynamic head $=$ Static Head + Dynamic Head

Thus "dynamic head" is due to the frictional fatalities in the channel and static depth due to the height of the water lift.

This TDH is one of the major parameter to be calculated for sizing of the pump.The whole procedure is depicted in figure 3 . 


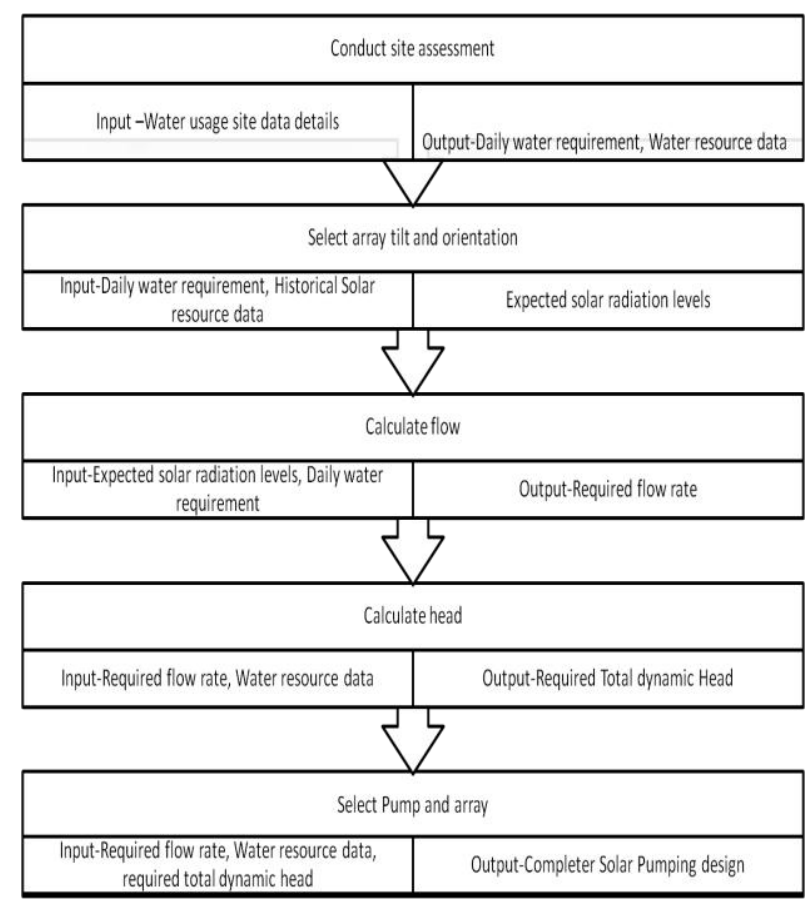

Figure 3:-Flowchart of design of water pumping system

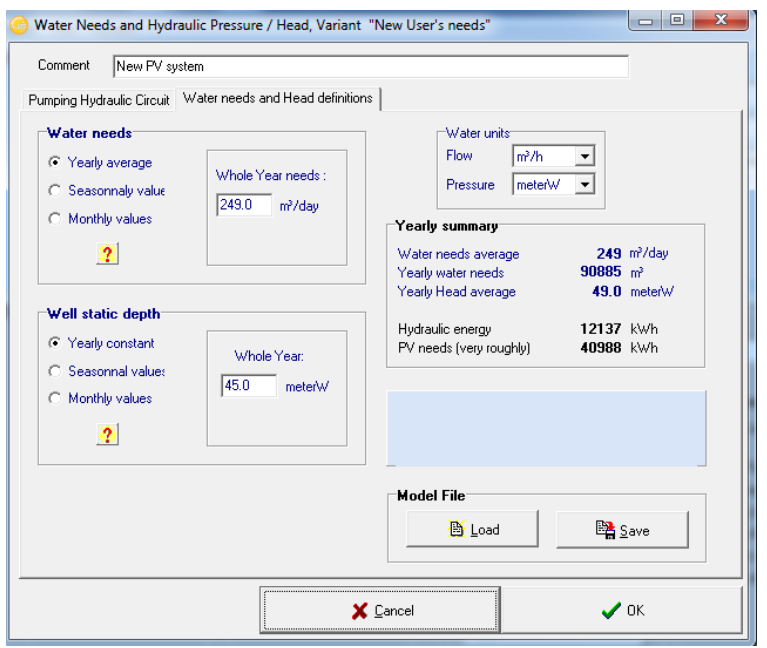

Figure 4:-Feeding of water needs in the software

\section{Storage}

Generally in all the installed sites water tank has been placed in the elevated position so as to aid the free flow of water by free outflow as in figure 4 Depending on the number of day there is unavailability of water size of the storage tank is selected. Mostly water is poured into the tank with the pipe outlet at top. Due to this kinetic energy is increased and residual pressure neglected. An efficiency can be improved by filling the tank through bottom

\section{Power conditioning and regulation}

The role of the Power conditioning unit is to match the output of the pv array to the appropriate form. Though in small pumping system Dc pumps are directly coupled with the PV array. It is simple but there is mismatch in the output[3].

The power converter plays the role the booster device. The reason for its requirement is that most of the displacement siphons require the high peak current at low voltage at the beginning in order to conquer the frictional powers because of the inner parts. 
For this purpose the boosters which is an electronic device are used which stores PV energy in a capacity and revert back as a peak current.

The use of DC-DC converter [4] is gaining the importance. The reason is the reduction in the price of semiconductor switches. This converter absorbs the power output of the PV array at a fixed voltage an it behave as a current generator for feeding the DC motor in the pump. The input voltage is chosen near to the maximum peak voltage and remains at that point for any value of irradiance [5] .In practical case input voltage to the converter is calibrated by the hardware. The performance of the system is only dependant on the PVarray and meteo files but does not depend on the pump configuration [6]. The power at the optimum current or voltage point is transferred to the pump motor corresponding to the available power Solar irradiations changes time to time in a day. In order to maximize the efficiency of the solar panel output it is need the find the position of the panel so that PV panel yields optimum. For this purpose maximum point tracking is necessary. DC-DC converters are employed for tracking the point of peak power. In PVsyst there is a tool the estimates the gain which is obtained by using MPPT the with respect to DC-DC converter for any PV position or any meteo location But using the MPPT converter increase the cost to some extent as in figure 5. [7]

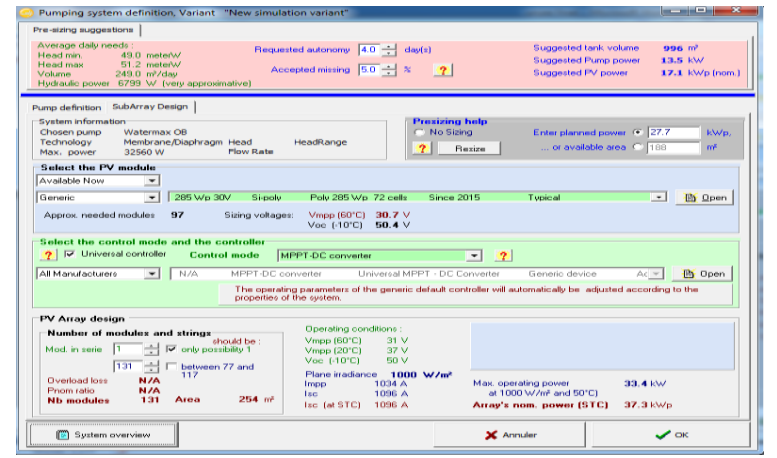

Figure 5:-Defining System in PVsyst

Some of the water pumps are driven by the AC motors and they need converters to convert the output of PV system in an appropriate form. Generally there is a dedicated converter coupled by motor .The solution to this is to use standard frequency converters which can be coupled to the any submersible centrifugal pumps. This broaden the scope as dedicated motor converter set is not there.

\section{Reconfiguration of PV Array}

The PV arrays are reconfigured to enhance the direct coupling mismatch. This can be achieved by considering connecting the PV modules in parallel at low irradiance so as to deliver the high flow to the pump required in the beginning]. At high irradiance the PV arrays are in the series arrangement multiplying the voltage and diminishing the current of the PV cluster. The high technological a switch is used for the required purpose [5].

\section{Cascading of the Pumps}

If there are several pumps cascaded then the regulation should be such that it should the pump should be ON depending on the availability[8] of the power. The pump that is being switched ON should run at or closer to the best possible efficiency[9]

\section{Battery Usage}

In spite of the fact that not frequently utilized as a result of its cost and upkeep prerequisites, batteries may control the power accessibility when utilizing DC-pumps[10]. The beginning peak current is no more an issue, and such a framework will work at consistent voltage, i.e. steady flow rate for a given head. This obviously streamlines the plan, and permits to utilize the PV[11] establishment in combination with other local, distinctive or modern apparatuses.

\section{Other strategies}

These framework setups will be treated in detail in the PVsyst software package. This suggests the UI's permits to serenely characterize the included parameters regardless, [12] and that relevant yield results are determined and made accessible. Different procedures might be explored, and will likewise be treated in PVsyst in a second step. 


\section{Conclusion:-}

In this paper it is concluded that lot of expertise is required for the accurate design of solar pumping systems. The researchers have documented the various design rules ,optimum options available and best practices followed .The PvSyst software aims to collect the information available and presents the platform available for presizing of the water pumping system so as to achieve the maximum efficiency. The software take the meteo files and option are available for designing the particular system which depends upon the daily needs, technology to be used and number of the solar panels to be required. By choosing the appropriate technology and the Photovoltaic system efficacy and the economic analysis can be done easily by using this software.

\section{Future Scope}

The software PVsyst is very advantageous in the presizing of the solar powered application. In the cost analysis and the efficiency of the system can be predetermined while laying the application and the performance of the system can be seen while changing the parameters and configuration. This software can also be implemented for the grid connected application. The different configurations of various sub module can be selected to find the optimum in the future work.

\section{References:-}

1. L. Navarte, E. Lorenzo, E. Caamaño "PV pumping analytical design and Characteristics of Boreholes". Solar Energy 68, no 1, pp 49-56, 2000.

2. J.A. Roger "Theory of the direct coupling between DC Motors and PV solar Arrays" Solar Energy 23, pp 193198, 1979.

3. M. Alonso-Abella, E. Lorenzo, F. Chenlo “ PVWater Pumping Systems based on Standard Frequency Converters" Progress in Photovoltaic Research and Applications 2003, 11:1-13.

4. M. Alonso-Abella, F. Chenlo, J. Blanco, D. Manso "Use of Standard Frequency Converters in PVpumping systems". 2nd World Conf. and Exhibitionon PVSEC, Vienna, 1998.

5. L.L. Kazmerski "Solar photovoltaic R\&D at the tipping point: A 2005 technology overview", Journal of Electron Spectroscopy and Related Phenomena, Vol. 150, 2006, pp. 105 - 135.

6. European Commission, DG Joint Research Centre, Institute for Environment and Sustainability, Renewable Energies Unit, "PV Status Report 2006", Ispra, Italy, 2006, EUR 22346 EN. Available at: http://re.jrc.ec.europa.eu/solarec/index.htm, Accessed on 15 June 2008.

7. IWMI, International Water Management Institute, "Insights from the Comprehensive Assessment of Water Management in Agriculture", Stockholm World Water Week, Stockholm, Sweden,2006,Available at: http://www.worldwaterweek.org, Accessedon 17 June 2008.

8. UNESCO, United Nations Educational, Scientific and CulturalOrganization, "A Thirsty World", 2001, Available athttp://www.unesco.org, Accessed on 16 June 2008.

9. J.K. Kaldellis, K.A.Kavadias, E. Kondili, "Renewable Energy Desalination Plants for the Greek Islands, Technical and Economic Considerations", Desalination Journal, Vol. 170, No. 2,2004, pp. 187 - 203.

10. V. Badescu "Time dependent model of a complex PV water pumping system", Renewable Energy, Vol. 28, 2003 , pp. $543-560$.

11. J.K. Kaldellis "Integrated Electrification Solution for Autonomous Electrical Networks on the Basis of RES and Energy Storage Configurations", , Energy Conversion and Management Jr,Available at: http://www.sciencedirect.com/, (15/08/2008). 